\title{
A case of congenital single testis with testicular cancer patient and azoospermia who was able to collect spermatozoa with ipsilateral Onco-TESE
}

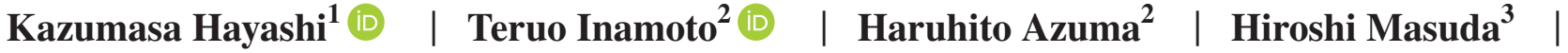 \\ Hirotsugu Oku ${ }^{4}$
}

\author{
${ }^{1}$ Department of Urology, Ishinkai Yao Sogo \\ Byoin, Yao, Japan \\ ${ }^{2}$ Department of Urology, Osaka Medical \\ College, Takatsuki, Japan \\ ${ }^{3}$ Department of Urology, Tesseikai \\ Neurosurgical Hospital, Shijyounawate, \\ Japan \\ ${ }^{4}$ Department of Urology, Ladies Clinic \\ Kitahama, Osaka, Japan

\section{Correspondence} \\ Kazumasa Hayashi, Department of Urology, \\ Ishinkai Yao Sogo Byoin, Yao, Osaka, \\ Japan. \\ Email: uro063@osaka-med.ac.jp
}

\begin{abstract}
Onco-TESE is a useful strategy for cancer patients with a congenital single testis who wish to preserve their fertility.
\end{abstract}

\section{K E Y W O R D S}

cancer patient, congenital single testis, Onco-TESE, testicular cancer

\section{1 | INTRODUCTION}

A young Japanese man presented with testicular cancer in a congenital single testis and was subsequently diagnosed with azoospermia. The patient underwent orchidectomy and simultaneous ipsilateral oncological-testicular sperm extraction, which collected viable sperm for cryopreservation. The sperm was used for intracytoplasmic sperm injection, and a healthy child was ultimately born.

Testicular germ cell tumors (TGCTs) are most commonly found in men who are 15-35 years old and account for 1.0$1.5 \%$ of neoplasms in men. ${ }^{1}$ Men have also had an increasing incidence of testicular dysgenesis syndrome (TDS, decreased spermatogenesis, hypospadias, cryptorchidism, and testicular tumors) during recent decades, and the four events are often interrelated. $^{2}$ Patients with TGCT can typically be cured, although postoperative chemotherapy and/or radiotherapy typically damage the healthy testis and result in infertility. Several researchers have recommended cryopreservation of sperm before treatment for $\mathrm{TGCT}^{3-5}$ as infertility can harm the mental health of young patients, and these patients may not have considered their fertility or plans to have children at the time of their TGCT diagnosis. Thus, pre-treatment cryopreservation of sperm may improve these patients' quality of life, even if the sperm is not ultimately used for assisted reproductive therapy. ${ }^{6}$ Furthermore, $75 \%$ of these patients have not had children at the time of their diagnosis and $>50 \%$ of patients with cured testicular tumors may desire a child after treatment. $^{7}$

Although the American Society of Clinical Oncology recommends sperm cryopreservation to preserve fertility in this setting, few patients receive infertility treatment, ${ }^{8}$ and studies at two major cancer centers revealed that only $51 \%$ of patients had completed sperm banking and only $24 \%$ of patients

This is an open access article under the terms of the Creative Commons Attribution License, which permits use, distribution and reproduction in any medium, provided the original work is properly cited.

(c) 2020 The Authors. Clinical Case Reports published by John Wiley \& Sons Ltd. 
actually had their sperm cryopreserved. ${ }^{9}$ Nevertheless, patients with TGCT have cure rate of 80-90\% after treatment using surgery, radiation, and chemotherapy, and an increasing trend has been identified, ${ }^{10}$ with strict follow-up and salvage therapy contributing to good outcomes. ${ }^{11-13}$ Onco-TESE is defined as a testicular sperm extraction in azoospermic cancer patients before chemotherapy that allows spermatozoa to be obtained from the normal testis of patients who do not emit sperm prior to cancer therapy to preserve and treat fertility in these men at the time of their orchiectomy. Therefore, oncologic testicular sperm extraction (Onco-TESE) might have value for preserving fertility among patients with TGCTs and azoospermia, as sperm that are identified in non-cancer tissues can be cryopreserved and subsequently used for assisted reproductive therapy. We describe our experience with a patient who had testicular cancer in a congenital single testis and was subsequently diagnosed with azoospermia. Ipsilateral Onco-TESE was performed simultaneously during radical orchiectomy and sperm was collected, cryopreserved, and subsequently used for intracytoplasmic sperm injection (ICSI). The patient's wife ultimately gave birth to a healthy child.

\section{2 | CASE PRESENTATION}

A 26-year-old Japanese man noticed painless enlargement of his right scrotum and visited the urology department at a nearby hospital. He had been diagnosed with cryptorchidism during childhood and had undergone laparotomy, which failed to identify his left testis and he was subsequently diagnosed with a left testicle defect. At his presentation, the right testis was swollen to a diameter of $5 \mathrm{~cm}$ and ultrasonography confirmed a $5 \mathrm{~cm}$ hypoechoic mass in the right testis. Plain computed tomography revealed a uniform approximately $5 \mathrm{~cm}$ mass inside the scrotum with no obvious metastasis. Laboratory tests revealed high concentrations of human chorionic gonadotropin (HCG: $16.6 \mathrm{mIU} / \mathrm{mL}$ ) and human chorionic gonadotropin- $\beta$ (HCG- $\beta$ : $0.46 \mathrm{ng} / \mathrm{mL}$ ), with nearly normal results for $\alpha$-fetoprotein $(2.3 \mathrm{ng} / \mathrm{mL})$, luteinizing hormone $(2.1 \mathrm{mIU} / \mathrm{mL})$, follicle-stimulating hormone $(4.7 \mathrm{mIU} /$ $\mathrm{mL})$, and testosterone (470 $\mathrm{ng} / \mathrm{dL})$.

The patient had a fiancé and wished to cryopreserve his sperm, although azoospermia was identified based on twice semen tests that were performed at the assisted reproductive therapy clinic. His karyotype and Y chromosome were normal and without microdeletions. He was referred to our hospital and underwent radical orchiectomy with planned sampling of any non-cancer seminiferous tubule tissue to collect sperm if possible. The orchiectomy revealed that most of the testicle was occupied by a gray-white mass without bleeding or necrosis (Figures 1 and 2), and the seminiferous tubule was visible to the naked eye between the tumor's head and the

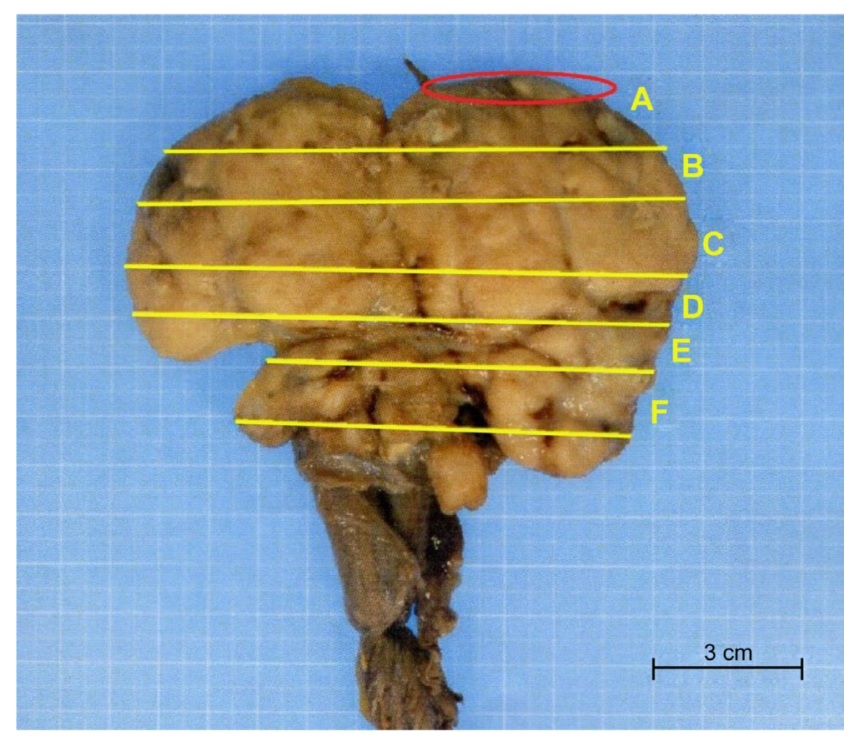

FIG URE 1 Most of the testis was occupied by the tumor. The seminiferous tubule was excluded by the tumor and clung to the tunica albuginea (near the red circle)

tunica albuginea. Thus, immediately after testis removal, we collected the seminiferous tubules in situ. We used an open technique that removes several small part of testicular tissue. Samples contained a large amount of cellular debris, including blood clots. Finding sperm in the testicular tissue took about 3 hours to process. The testicular tissue was evaluated under a stereomicroscope to identify seminiferous tubules and remove blood clots. Distribution and localization of seminiferous tubules containing spermatogenesis among the normal tissue were in diffuse fashion. Following identification, the testicular sample was processed by dispersion of the tubules through mechanical homogenization. Thereafter, the sample was evaluated using the inverted microscope (400x magnification) to identify the presence of morphologically normal and motile sperm (Figure 3). Approximately $0.5 \mathrm{~g}$ of tissue was collected, divided into 10 tubes, and we have sent the rest of resected testicular tissue to the cryopreservation laboratory. The excised testicular tumor was about $12 \mathrm{~cm}$ in diameter.

Histopathological examination revealed tumor cells that contained lymphocytes and clear cytoplasm, which supported a diagnosis of pure seminoma (pT1N0M0) (Figure 4). Spermatogenesis was confirmed in a portion of the normal seminiferous tubules (Figure 5). The seminiferous tubules had uniform thickness throughout and diffuse spermatogenesis. The Johnson score was 8 .

The patient's postoperative course was uneventful, with normalization of his HCG and HCG- $\beta$ concentrations. No adjuvant therapy was performed, although close follow-up was performed using imaging and blood tests. No obvious tumor recurrence has been observed, and the patient is receiving continuous testosterone supplementation because of 
FIGURE 2 Cut surfaces of the tumor. The red line is the one used for histopathological examination

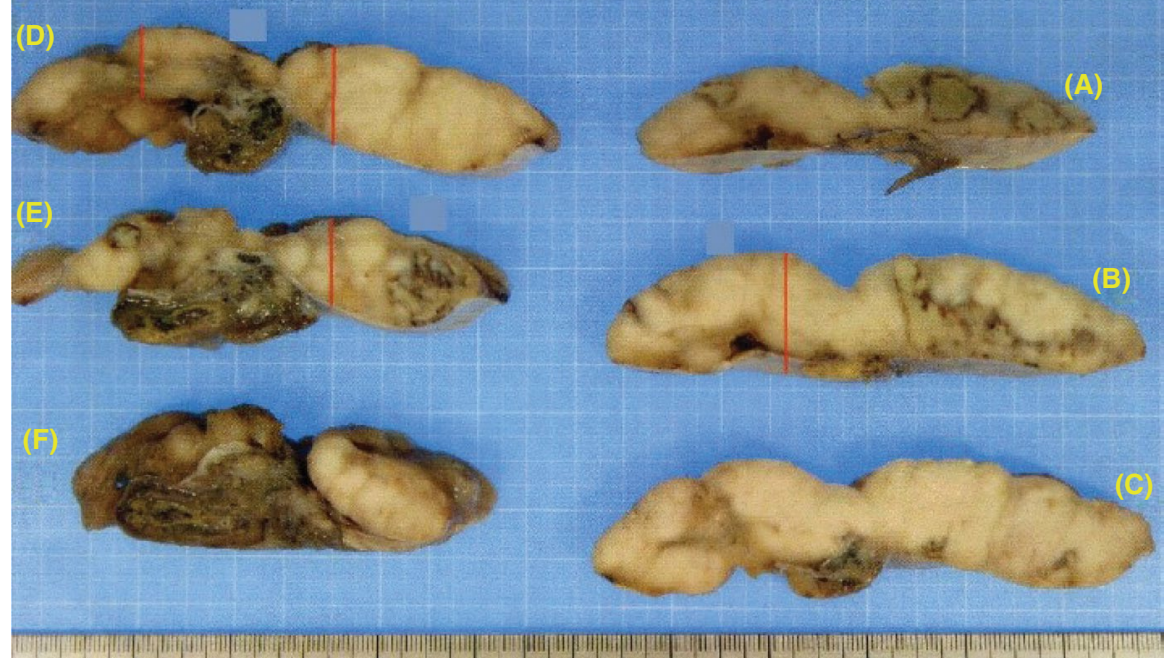

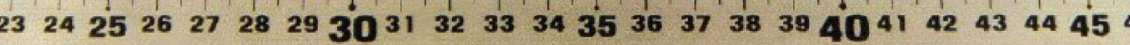

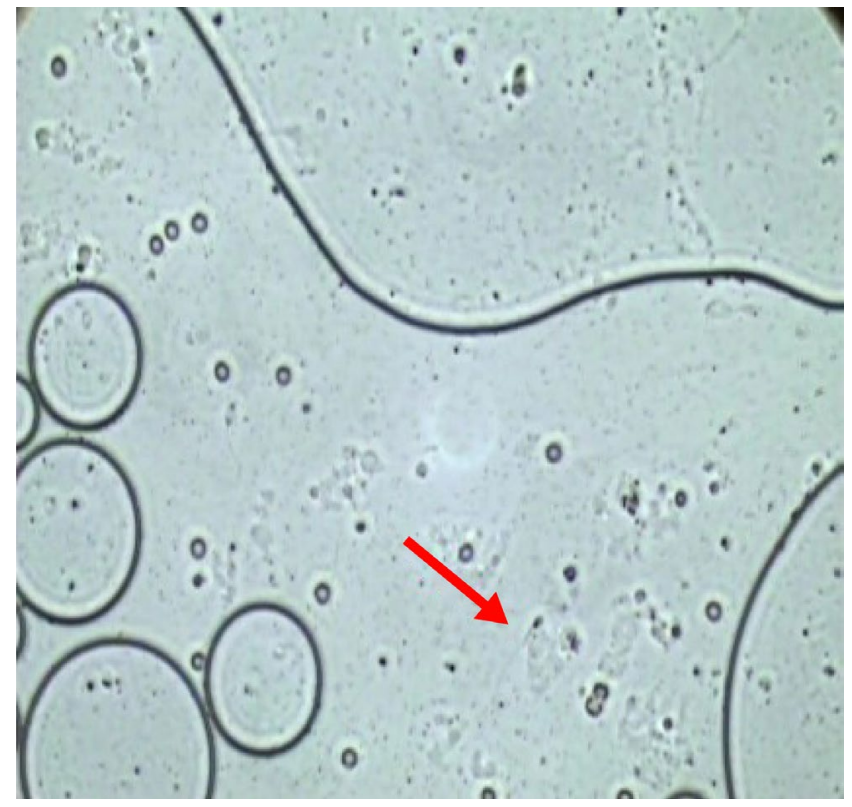

F I G URE 3 Sperm could be identified using an inverted microscope $(\times 1000)$

low testosterone concentrations after the orchiectomy. The patient subsequently married his fiancé, who had normal gynecological findings based on hysteroscopy, transvaginal ultrasonography, and blood tests. Thus, ICSI was performed using the cryopreserved sperm, the wife became pregnant, and a healthy boy was born on gestational week $39+3$ (birth weight: $3,060 \mathrm{~g}$, no TDS syndrome).

\section{3 | DISCUSSION}

In this case, the patient was preoperatively diagnosed with azoospermia, and onco-TESE was the only option to preserve his fertility because the congenital single testis needed to be

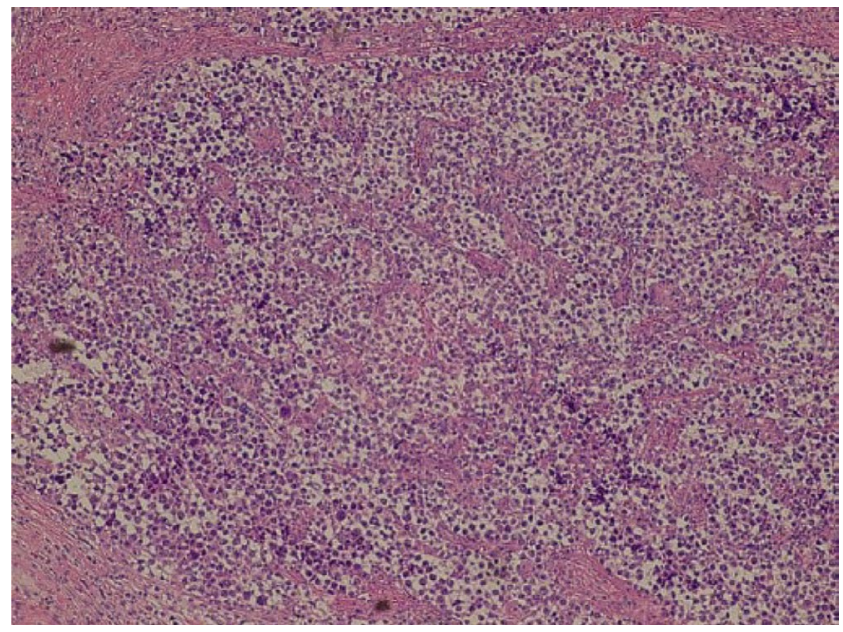

F I G U R E 4 Hematoxylin and eosin staining $(\times 400)$ revealed tumor cells containing lymphocytes and clear cytoplasm

removed. Testicular tumors are generally associated with decreased spermatogenesis, with patients having approximately $33 \%$ of the sperm concentration and $17 \%$ of the total sperm count, relative to men in the general population. ${ }^{14}$ The effects on spermatogenesis are pronounced after chemotherapy, although recovered spermatogenesis has been identified in $75 \%$ of patients after 18 months. ${ }^{15}$ However, this would not have been possible in our case, given the removal of his congenital single testis.

The reported frequency of congenital single testis diagnosed during surgery for cryptorchidism is $4 \%$ in Europe and the United States. ${ }^{16}$ However, assisted reproductive technology has improved in recent years, and these patients may be able to preserve their fertility using cryopreserved sperm. ${ }^{17,18}$ Several groups ${ }^{6,19-21}$ have reported that Onco-TESE is possible in patients with azoospermia and testicular cancer, which may allow the cryopreserved sperm to be used with assisted reproduction to achieve the birth of a healthy baby. However, 


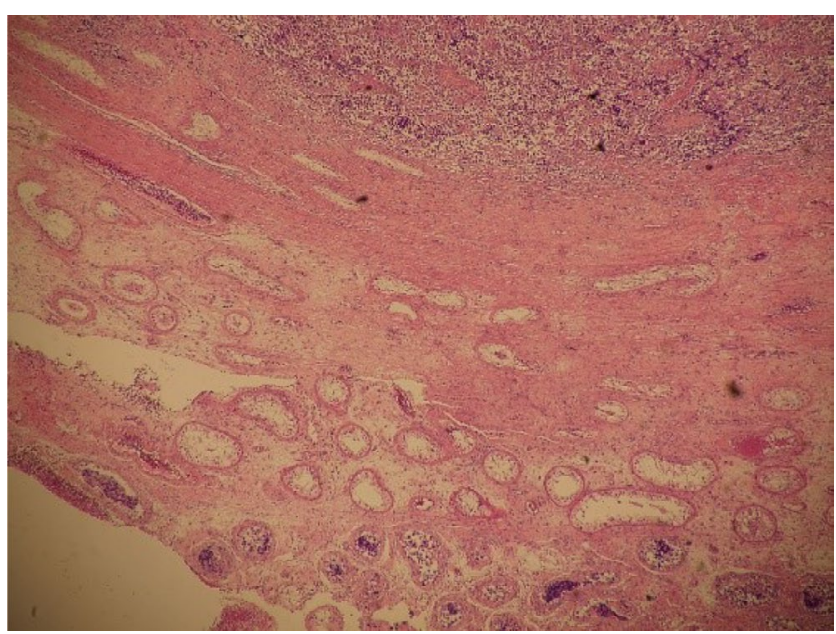

FIGURE 5 Seminiferous tubules were observed between the head of the tumor and the tunica albuginea $(\times 100)$

we are not aware of any reports that have described this strategy in a patient with testicular cancer involving a congenital single testis.

\section{4 | CONCLUSION}

We performed Onco-TESE during radical orchiectomy and were able to preserve the fertility of a patient with a congenital single testis. This technique successfully retrieved sperm that were cryopreserved and used for ICSI, which ultimately resulted in the birth of a healthy child. Therefore, Onco-TESE is a useful strategy for cancer patients with a congenital single testis who wish to preserve their fertility.

\section{ACKNOWLEDGMENTS}

We thank the patient, his wife, and everyone involved in the patient's treatment. The patient provided written consent for the publication of this report.

\section{CONFLICT OF INTEREST}

None declared.

\section{AUTHOR CONTRIBUTIONS}

All authors: read and reviewed the manuscript. HM: performed the orchidectomy, Onco-TESE, and postoperative follow-up. TI and HA: reviewed the manuscript. HO: referred the patient to our clinic and successfully performed ICSI with the cryopreserved sperm.

\section{DATA AVAILABILITY STATEMENT}

The data that support the findings of this study are available on request from the corresponding author. The data are not publicly available due to privacy or ethical restrictions.

\section{ORCID}

Kazumasa Hayashi (iD https://orcid.

org/0000-0002-1807-0256

Teruo Inamoto (D) https://orcid.org/0000-0002-1351-1315

\section{REFERENCES}

1. Fraietta R, Spaine DM, Bertolla RP, Ortiz V, Cedenho AP. Individual and seminal characteristics of patients with testicular germ cell tumors. Fertil Steril. 2010;94(6):2107-2112. https://doi. org/10.1016/j.fertnstert.2009.12.021

2. Skakkebæk NE, Rajpert-De Meyts E, Main KM. Testicular dysgenesis syndrome: an increasingly common developmental disorder with environmental aspects: Opinion. Hum Reprod. 2001;16(5):972-978. https://doi.org/10.1093/humrep/16.5.972

3. Horwich A, Shipley J, Huddart R. Testicular germ-cell cancer. Lancet. 2006;367(9512):754-765. https://doi.org/10.1016/ S0140-6736(06)68305-0

4. Møller H, Skakkebæk NE. Risk of testicular cancer in subfertile men: case-control study. BMJ. 1999;318(7183):559-562.

5. Rives N, Perdrix A, Hennebicq S, et al. The semen quality of 1158 men with testicular cancer at the time of cryopreservation: results of the French National CECOS Network. J Androl. 2012;33(6):13941401. https://doi.org/10.2164/jandrol.112.016592

6. Ostad M, Liotta D, Ye Z, Schlegel PN. Testicular sperm extraction for nonobstructive azoospermia: results of a multibiopsy approach with optimized tissue dispersion. Urology. 1998;52(4):692-696. https://doi.org/10.1016/s0090-4295(98)00322-7

7. Schover LR, Brey K, Lichtin A, Lipshultz LI, Jeha S. Knowledge and experience regarding cancer, infertility, and sperm banking in younger male survivors. J Clin Oncol. 2002;20(7):1880-1889. https://doi.org/10.1200/JCO.2002.07.175

8. Oktay K, Harvey BE, Partridge AH, et al. Fertility preservation in patients with cancer: ASCO clinical practice guideline update. JCO. 2018;36(19):1994-2001. https://doi.org/10.1200/ JCO.2018.78.1914

9. Quinn GP, Vadaparampil ST, Lee JH, et al. Physician referral for fertility preservation in oncology patients: a national study of practice behaviors. J Clin Oncol. 2009;27(35):5952-5957. https://doi. org/10.1200/JCO.2009.23.0250

10. Chaudhary UB, Haldas JR. Long-term complications of chemotherapy for germ cell tumours. Drugs. 2003;63(15):1565-1577. https://doi.org/10.2165/00003495-200363150-00004

11. Souchon R, Krege S, Schmoll HJ, et al. Interdisciplinary consensus on diagnosis and therapy of testicular tumors. Results of an update conference based on evidence-based medicine. German Testicular Cancer study Group (GTCSG). Strahlenther Onkol. 2000;176(9):388-405.

12. Aareleid T, Sant M, Hédelin G. Improved survival for patients with testicular cancer in Europe since 1978. EUROCARE Working Group. Eur J Cancer. 1998;34(14 Spec No):2236-2240. https:// doi.org/10.1016/S0959-8049(98)00313-X

13. Albers $\mathrm{P}$, Albrecht $\mathrm{W}$, Algaba F, et al. EAU guidelines on testicular cancer: 2011 update. Eur Urol. 2011;60(2):304-319. https://doi. org/10.1016/j.eururo.2011.05.038

14. Petersen PM, Skakkebaek NE, Vistisen K, Rørth M, Giwercman A. Semen quality and reproductive hormones before orchiectomy in men with testicular cancer. J Clin Oncol. 1999;17(3):941-947. https://doi.org/10.1200/JCO.1999.17.3.941 
15. Lange PH, Narayan P, Vogelzang NJ, Shafer RB, Kennedy BJ, Fraley EE. Return of fertility after treatment for nonseminomatous testicular cancer: changing concepts. J Urol. 1983;129(6):11311135. https://doi.org/10.1016/s0022-5347(17)52607-5

16. Levitt SB, Kogan SJ, Engel RM, Weiss RM, Martin DC, Ehrlich RM. The impalpable testis: a rational approach to management. J Urol. 1978;120(5):515-520. https://doi.org/10.1016/ s0022-5347(17)57256-0

17. Palermo GD, Cohen J, Alikani M, Adler A, Rosenwaks Z. Intracytoplasmic sperm injection: a novel treatment for all forms of male factor infertility. Fertil Steril. 1995;63(6):1231-1240. https:// doi.org/10.1016/S0015-0282(16)57603-1

18. Matsushita K, Yamaguchi K, Li F, et al. Achieved pregnancy with the delivery of a healthy child by TESE-ICSI 7 years after bilateral adult orchidopexy: a case report. Andrologia. 2014;46(8):948-950. https://doi.org/10.1111/and.12174

19. Roque M, Sampaio M, de Oliveira Salles PG, Geber S. Oncotesticular sperm extraction: birth of a healthy baby after fertility preservation in synchronous bilateral testicular cancer and azoospermia. Andrologia. 2015;47(4):482-485. https://doi. org/10.1111/and.12292
20. Verhoeven RH, Coebergh JW, Kiemeney LA, Koldewijn EL, Houterman S. Testicular cancer: trends in mortality are well explained by changes in treatment and survival in the southern Netherlands since 1970. Eur J Cancer. 2007;43(17):2553-2558. https://doi.org/10.1016/j.ejca.2007.08.022

21. Hamano I, Hatakeyama S, Nakamura R. Onco-testicular sperm extraction (Onco-TESE) from a single testis with metachronous bilateral testicular cancer: a case report. Basic Clin Androl. 2018;28(1). http://dx.doi.org/10.1186/s12610-018-0066-2

How to cite this article: Hayashi $\mathrm{K}$, Inamoto $\mathrm{T}$, Azuma H, Masuda H, Oku H. A case of congenital single testis with testicular cancer patient and azoospermia who was able to collect spermatozoa with ipsilateral Onco-TESE. Clin Case Rep. 2021;9:535-539. https://doi.org/10.1002/ccr3.3576 